\title{
A realization of super-fast scanning power supply for Proton Therapy
}

\author{
Jiazhe $\mathrm{Li}^{1,2,3}$, Rui Li ${ }^{1}$, Huanting $\mathrm{Lu}^{2}$
}

Abstract This paper introduces a method to achieve fast scanning power supply for Proton Therapy. To meet the specific needs of this power supply, a new structure consists of dynamic module (high voltage part) and static module (low voltage part) has been designed and tested. The simulation results and actual waveform were listed in this paper. The results showed that the current rising slope can reach $90 \mathrm{kA} / \mathrm{s}$.

key words: fast scanning, loop switching, high precision, high current rising slope

Classification: Power devices and circuits

\section{Introduction}

Proton Therapy has attracted growing interest for cancer treatment $[1,2,3,4]$. Several Proton Therapy treatment centers have already put into service $[5,6,7]$. Typical way like radiotherapy and chemotherapy will largely harm healthy cells [8]. Because Proton beam will release its energy on specific depth due to" Bragg Peak" effect, which rarely affect healthy cells [9]. During the treatment, the Proton beam produced by accelerator will be bended by scanning power supply and shoot precisely on tumor cells. But unlike traditional high precision magnet power supply $[10,11,12,13,14]$, the scanning power supply for Proton Therapy requires a high dynamic response as well as high precision $[15,16,17,18]$. This means the duty cycle of a single power supply must varies a lot in a very short period, which is hard for

\footnotetext{
${ }^{1}$ Dept. of Mechanical and Electronics, Chinese Academy of Science, Shanghai Advanced Research Institute, Shanghai 201204, China

${ }^{2}$ Dept. of Applied Particle Accelerator, Chinese Academy of Science, Shanghai Institute of applied physics, Shanghai 201800, China

${ }^{3}$ University of Chinese Academy of Science, Beijing 100049, China

a) $\underline{\text { ivon93@mail.ustc.edu.cn }}$
}

DOI: $10.1587 /$ elex.18.20210501

Received November 25, 2021

Accepted December 06, 2021

Publicized December 24, 2021 digital control system to achieve technically [19,20,21]. This article mainly describes the design and achievement of fast scanning power supply for Proton Therapy. The context includes the topology, the control design, the simulation, and the hardware testing.

Table 1 Power supply characteristic data.

\begin{tabular}{l|l}
\hline Power Supply & SCAN-V-Power Supply \\
\hline Current Range $(\mathrm{A})$ & \pm 700 \\
\hline Load Inductance $(\mathrm{mH})$ & $3.876 \pm 10 \%$ \\
\hline Load Resistance $(\mathrm{m} \Omega)$ & $12.4 \pm 10 \%$ \\
\hline Step Size $(\mathrm{A})$ & $13.4 \pm 30 \%$ \\
\hline Current Rising Slope $(\mathrm{kA} / \mathrm{s})$ & 90 \\
\hline Ripple Current $(\mathrm{ppm})$ & 100 \\
\hline
\end{tabular}

\section{Basic structure}

The static module needs to produce high precision low ripple current on steady state [22], by referring to the load characteristic the load voltage (maximum current steady state) is

$V_{\text {load }(\text { steady }}$ state $)=R_{\text {load }} \times I_{\max }=700 \times 12.4 \times$ $10^{-3}=8.68 \mathrm{~V}$

Meanwhile, the load current also requires a fast-jumping performance [23]. Suppose the high voltage can perfectly drive the load current to its reference number. The least required load voltage for each current rising step is

$V_{\text {load(high_voltage })}=L_{\text {load }} \times \frac{d i}{d t}=3.876 \times 10^{-3} \times 90 \times$ $10^{3}=348.84 \mathrm{~V}$

Combining high voltage DC/DC convertor and low voltage $\mathrm{DC} / \mathrm{DC}$ convertor together can satisfy these needs.

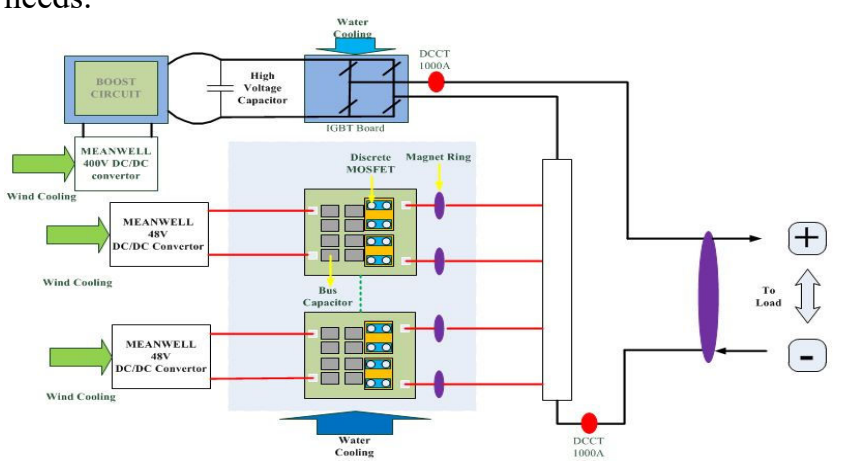

Fig. 1 Basic structure of super-fast scanning power supply 
As Fig.1 shows six 48V full-bridge circuits worked in parallel to produce a $700 \mathrm{~A}$ high precision current, a $1200 \mathrm{~V}$ full bridge circuit series with these low voltage full-bridge circuits. Each static module full-bridge circuit has two magnet rings attach to its output to eliminate the voltage differences caused by signal transmission delay and bus voltage differences. Two DCCT (DC current transducer) send current data back to control card [24,25].

\section{Control strategy}

The control strategy of the entire power supply is:

(1)The ADC card will sample the high voltage capacitor voltage and send it directly to FPGA control card.

(2) If $I_{\text {ref }}-I_{\text {measure }}>2 \mathrm{~A}$, for each current step, the FPGA card use the sampling voltage number only at the beginning of calculation process. FPGA card will calculate the time consumption for current step from $I_{\text {measure }}$ to $I_{\text {ref }}$ by

$\Delta t=\frac{L}{V_{\text {high voltage capacitor }}} \times\left(I_{\text {ref }}-I_{\text {measure }}\right)$

The IGBT full-bridge circuit will load the high voltage on both terminals of magnet load for $\Delta t$. The PI loop's output duty cycle is restricted by the upper limit duty cycle $D_{\max }$ and max duty rate of change $\frac{d D}{d t}$.

(3) After $\Delta t$ the low voltage module will transform into closed loop again adjusting the output current accurately to $I_{r e f}$.

\section{Static module performance}

Static module consists of six phase-shifted full-bridge circuits. The steady state ripple current ratio can be calculated by

$\lambda=\frac{I_{\text {ripple }}}{I_{\text {load }}}=\frac{V_{\text {peak-peak }}}{2 \times \pi \times \mathrm{f}_{\text {equivalent }} \times \mathrm{L} \times I_{\text {load }}}$

By adopting phase-shifted full-bridge control of static module, the equivalent switching frequency is twice the switching frequency of MOSFET [27]. This will largely decrease the ripple current ratio of the load [28].

To increase the adjusting speed of output voltage, the capacitor has been removed from the circuit.

The transfer function of duty ratio to output current of static module is

$G_{i d}(s)=\left.\frac{\hat{i}(s)}{\hat{d}^{(s)}}\right|_{v_{g}(s)=0}=\frac{V_{g} / R}{1+\frac{L}{R} s}$

The DCCT's (DC Current Transformer)transformation ratio of is $1: 2000$, while the sampling resistor is $10 \Omega$, the transfer function of sampling network is

$H(s)=\frac{1}{2000} \times 10=\frac{1}{200}$

The amplitude of PWM modulating signal is $5 \mathrm{~V}$, PWM modulator transfer function is

$V_{m}(s)=\frac{1}{5}$
The open loop transfer function of each full bridge phase-shift circuit is

$G_{\text {openloop }}(s)=G_{\text {id }}(s) \times V_{m}(s) \times H(s)=$ $\frac{48}{S \times 3.876 \times 10^{-3}+12.4 \times 10^{-3}} \times \frac{1}{200} \times \frac{1}{5}$

It can be calculated that the cut-off frequency of this transfer function is about $2 \mathrm{~Hz}$.

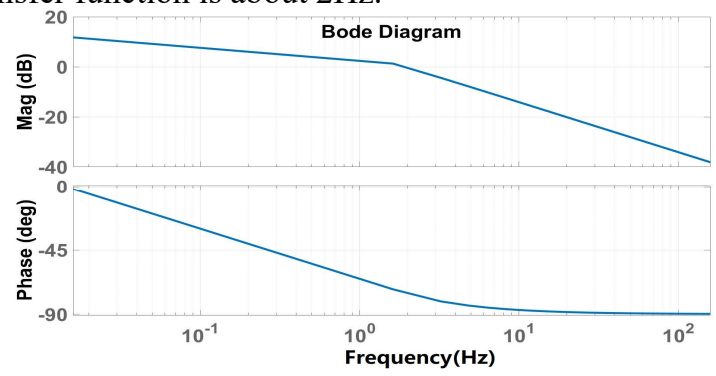

Fig. 2 Bode plot of static module transfer function

The bandwidth of open loop function is $0.135 \mathrm{~Hz}$. According to the relationship between control loop bandwidth and response time [29], the response time of this part is too low for a quick response.

$t_{r}=\frac{0.35}{B_{\text {bandwidth }}}$

Time consumption for a single phase-shifted full bridge circuit is 2.5926 seconds. The compensation loop in control card uses PI compensation will add a pole to transfer on low frequency band. The entire system will transform from a zero-order system into a first-order system. The steady state error $e_{s s}$ will reduced to 0 [30].

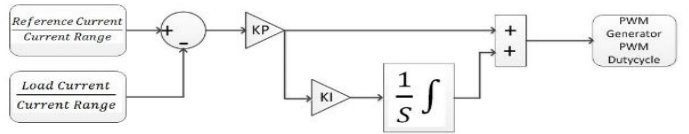

Fig. 3 Simplified PI compensation loop of control card

The transfer function of PI compensation loop is

$G_{c}(s)=K P+\frac{K P \times K I}{s}$

Increasing the product of KP and KI will shift right the cut-off frequency point of the entire system to increase the bandwidth of the static module to match dynamic module.

\section{Dynamic module performance}

For each current step the total time consumption is

$\Delta t=\frac{13.4}{90 \times 10^{3}} \approx 148.9 \mu \mathrm{s}$

Suppose MOSFET's switching frequency is $65 \mathrm{kHz}$, this power supply needs $5 \mathrm{PWM}$ periods for adjustment.

$t_{\text {mosfet_pwm }}=\frac{1}{65 \times 10^{3}} \times 5 \approx 76.9 \mu \mathrm{s}$

It takes about $20 \mu \mathrm{s}$ for a command signal send from host computer to console computer.

The reserve time for dynamic module is

$t_{\text {reserved }}=148.9-76.9-20=52 \mu \mathrm{s}$ 
Dynamic module's output voltage will directly attach to load terminals according to

$V_{\text {dynamic_module_bus_voltage }}=L \frac{d i}{d t}$

The minimum bus voltage for dynamic module is

$V_{\text {min }}=3.876 \times 10^{-3} \times \frac{13.4}{52 \mu s} \approx 998.8 \mathrm{~V}$

There are two parameters will affect the time consumption of each current step. One is the bus voltage of dynamic module, the other is the $\Delta i=I_{\text {ref }}-I_{\text {load }}$ after $\Delta t$.

Because each current step the control card only samples the dynamic bus voltage once, it is critical to maintain the bus voltage of dynamic module. According to

$\frac{1}{2} \times C_{\text {high_voltage }} \times\left(U_{0}^{2}-U_{c}^{2}\right)=\frac{1}{2} \times L_{\text {load }} \times\left(I_{c}^{2}-I_{0}^{2}\right)$

$I_{c}-I_{0}=\Delta i$

The most energy consumption condition is $I_{\text {ref }}$ jumps from $686.6 \mathrm{~A}$ to $700 \mathrm{~A}$ (or $-686.6 \mathrm{~A}$ to $-700 \mathrm{~A}$ ). Setting the capacitance of high voltage capacitor to $9.15 \mathrm{mF}$, initial voltage is $1200 \mathrm{~V}$. It can be calculated

$U_{c} \approx 1196.7 \mathrm{~V}$

5.1 Dynamic loop circuit

Because the actual tumor cells randomly distributed in human body. The energy stored in the load inductor during current positive jumps may restore to dynamic module's bus capacitor when current step negative jumps. Therefore, the boost convertor doesn't need to react quickly to its output voltage.

We use a $400 \mathrm{~V}$ DC/DC convertor and a boost convert to produce $1200 \mathrm{~V}$ bus voltage for dynamic module. Inductor's current upper limit was set to $0.8 \mathrm{~A}$.

The advantages of adopting this scheme are:(1)Modular design reduces the volume of transformer;(2)Wide range of output voltage variation.

\subsection{Simulation of current jump}

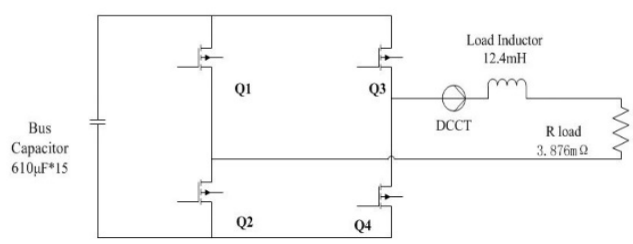

Fig. 4 Dynamic module full-bridge circuit

The equivalent circuit is an RLC circuit when dynamic loop cut in.

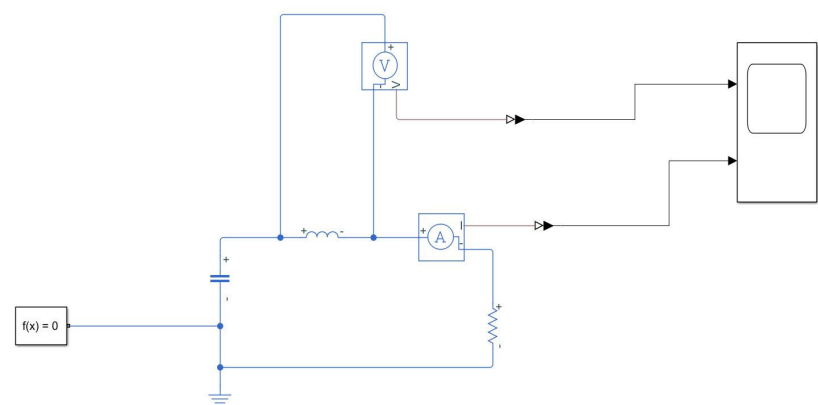

Fig. 5 Equivalent circuit when dynamic loop cut in

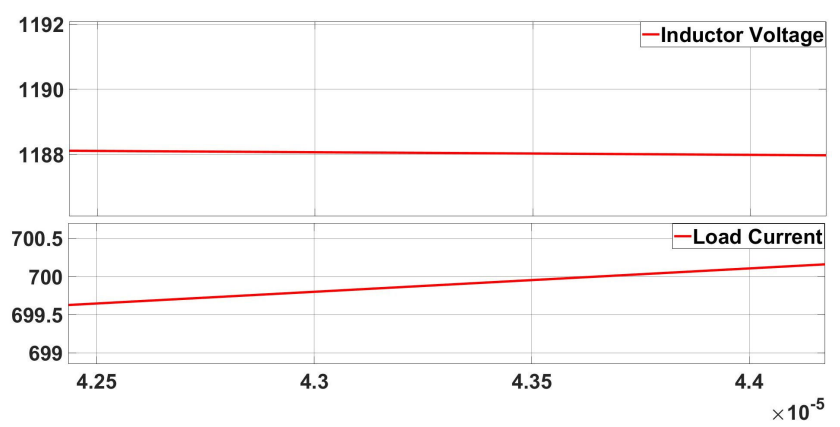

Fig. 6 Simulation results of equivalent circuit

If the bus voltage of dynamic module is a constant number $V_{\text {bus_voltage }}=1200 \mathrm{~V}$, time consumption for a current step is

$\Delta t=\frac{L_{\text {load }}}{V_{\text {dynamic_bus_voltage }}} \times \Delta i=\frac{3.876 \times 10^{-3}}{1200} \times 13.4 \approx$

$43.3 \mu s$

But the bus voltage was supplied by the capacitors.

After $\Delta t$ the calculation results of output current difference between actual condition and ideal condition $I_{\text {difference }}=0.1 \mathrm{~A}$.

Table II. Control Logic of Dynamic module full-bridge circuit

\begin{tabular}{l|l|l|l|l}
\hline & Q1 & Q2 & Q3 & Q4 \\
\hline $\begin{array}{l}\text { Current } \\
\text { Rise }\end{array}$ & 0 & 1 & 1 & 0 \\
\hline $\begin{array}{l}\text { Current } \\
\text { Fall }\end{array}$ & 0 & 1 & 0 & 1 \\
\hline $\begin{array}{l}\text { Steady } \\
\text { State }\end{array}$ & 1 & 0 & 0 & 1 \\
\hline
\end{tabular}

Simulation strategy on MATLAB Simulink:

Because the parasitic parameter of transmission line, the propagation delay from control card to IGBT driver, the turn-on and turn-off delay of IGBT, the $I_{\text {difference }}$ for different current step is not exactly equal, the nonlinearity of inductor also affects the adjusting time.

Therefore, the current differences $I_{\text {difference }}$ will become larger than pervious calculation results. Therefore, we set $I_{\text {difference }}=0.3 \mathrm{~A}$.

The method to test which one is more dominant on time consumption are: (1)bus voltage increased to $1400 \mathrm{~V}$. (2) current difference decreased to $0.1 \mathrm{~A}$.

Setting a threshold for dynamic loop control center. If $I_{\text {difference }}$ is bigger than threshold, dynamic loop cut in, 
IEICE Electronics Express, Vol.xx, No.xx, xx-xx

else dynamic loop cut out.

The simulation aims at testing whether each current jump can meet the time requirements of Table 1 . We need to observe the load current varies form 0A-13.4A and 686.6A-700A, especially when current jumps from $686.6 \mathrm{~A}$ to $700 \mathrm{~A}$.

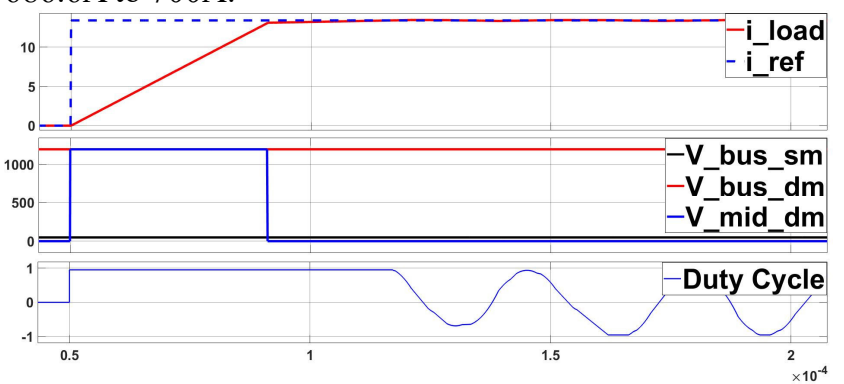

Fig. 7 Load current jumps from 0A to 13.4A

Fig.7 shows when $I_{\text {difference }}=0.3 \mathrm{~A}$ dynamic module bus voltage equals $1200 \mathrm{~V}$, it takes about $70.117 \mu \mathrm{s}$ for the entire system to adjust its output current to $I_{\text {ref }}$.
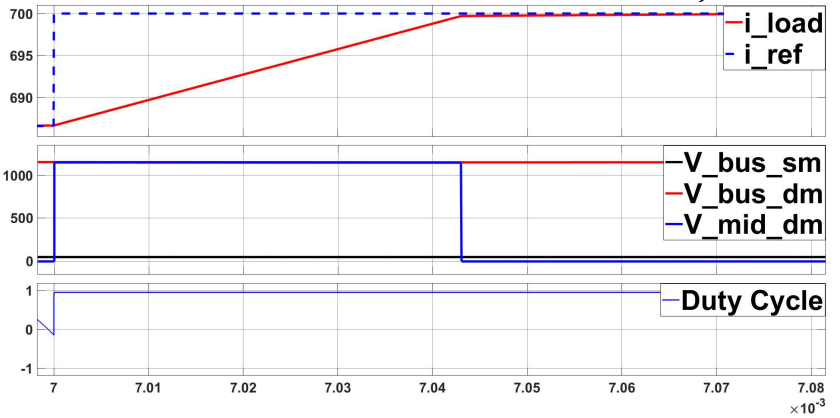

Fig.8 Load current jumps from 686.6A to 700A

Fig. 8 shows that the total time consumption from $686.6 \mathrm{~A}$ to $700 \mathrm{~A}$ is $79.914 \mu \mathrm{s}$.

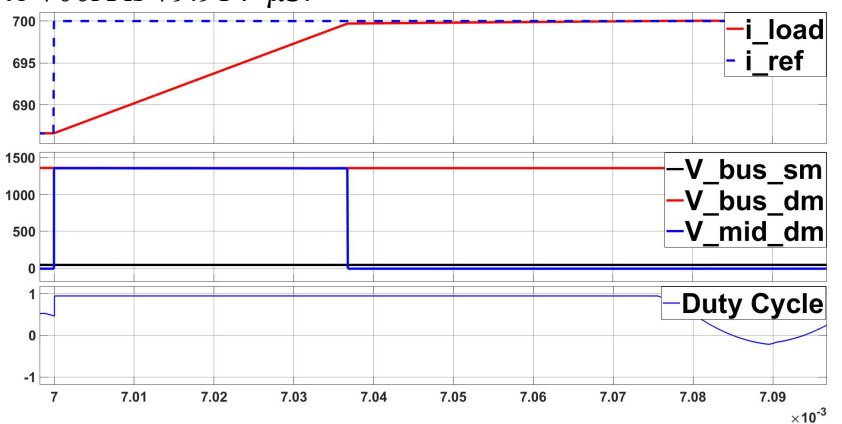

Fig. 9 Dynamic module bus voltage equals to $1400 \mathrm{~V}$

Fig.9 shows that dynamic module bus voltage increases to $1400 \mathrm{~V}, I_{\text {difference }}=0.3 \mathrm{~A}$, load current jumps from $686.6 \mathrm{~A}$ to $700 \mathrm{~A}$, the time consumption for entire process is $77.453 \mu \mathrm{s}$.

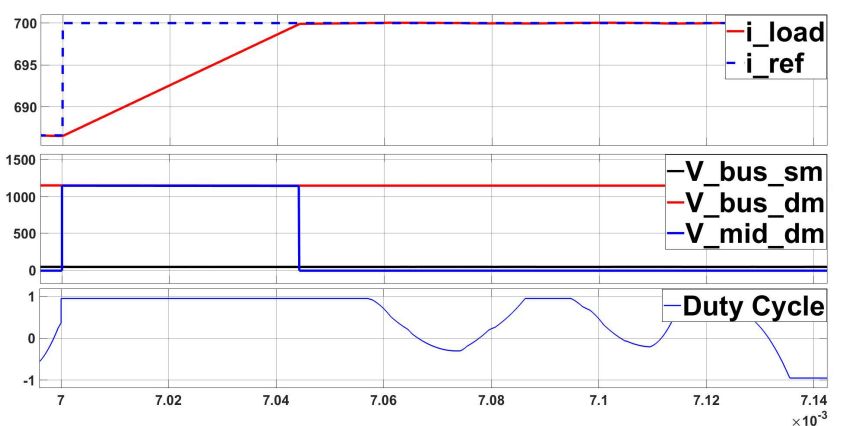

Fig. 10 Load current jumps from 686.6A to 700A

Fig.10 shows when $I_{\text {difference }}=0.1 A$, the dynamic bus voltage equals to $1200 \mathrm{~V}$, the load current jumps form $686.6 \mathrm{~A}$ to $700 \mathrm{~A}$. The total time consumption decreases to $54.681 \mu \mathrm{s}$. This comparison shows that decrease current difference $I_{\text {difference }}$ is more effective than increase bus voltage.

\section{Actual Performance}

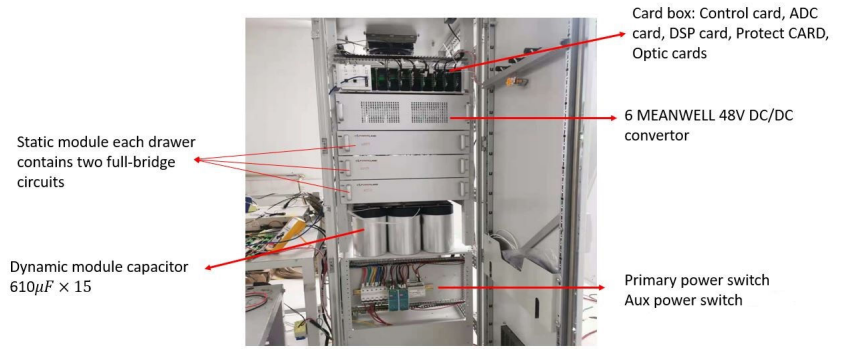

Fig. 11 Front view of SCAN-V power supply

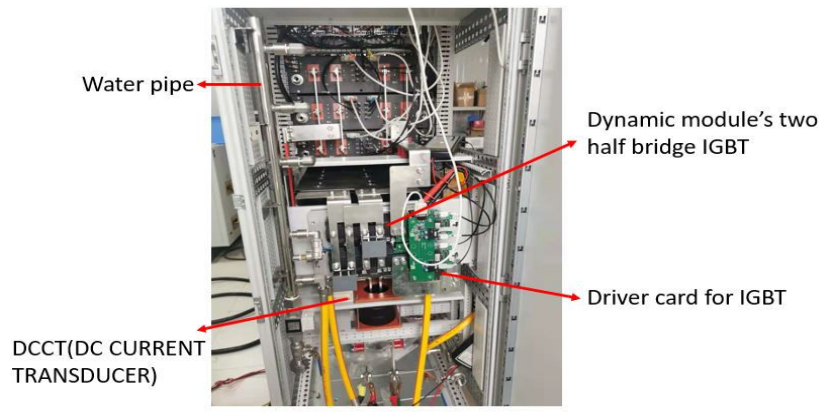

Fig. 12 Rear view of SCAN-V power supply

The overall structure of super-fast scanning power supply is showing in Fig.11 and Fig.12. Modular design was adopted by static module of this power supply to increase the stability. The combination of DC/DC convertor and boost convertor produce high voltage for dynamic module.

The $V_{c e(s a t)}$ of IGBT is $2 \mathrm{~V}\left(T_{v j}=25^{\circ} \mathrm{C}\right)$, the maximum current of dynamic module is $700 \mathrm{~A}$. Therefore, a watercooling board was attached to both IGBT half-bridges. 
The actual magnet load is still being built. So, we choose a $12 \mathrm{~m} \Omega, 4 \mathrm{mH}$ dummy load instead.

The control card set the max changing ratio and upper limit and lower limit of static module's MOSFET. when current jumps positively, static module will become an open loop and the duty cycle of static module's MOSFET will reach its upper limit in the meantime the dynamic module cut in. Once dynamic loop cut-off, the duty cycle of static module's MOSFET will gradually decrease to its target.

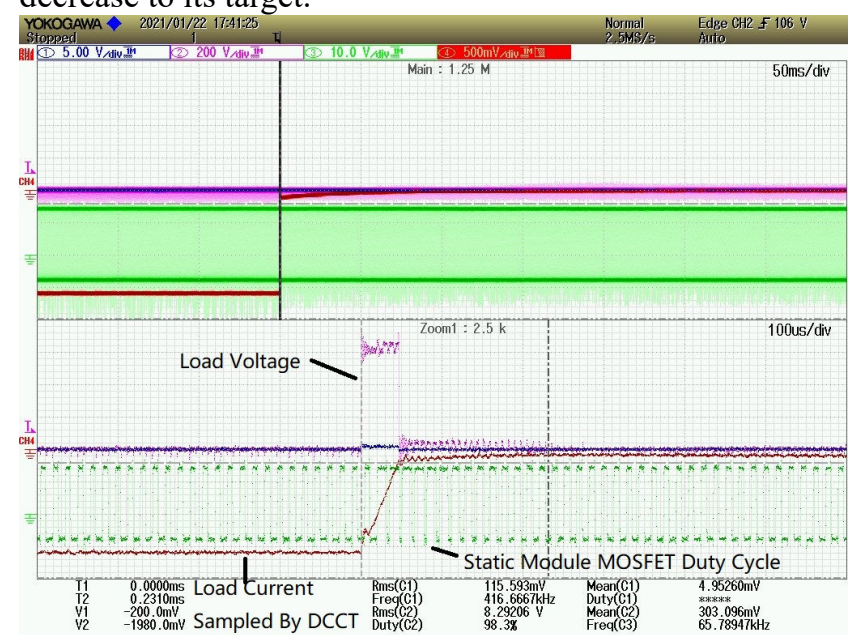

Fig. 13 Static module's MOSFET duty quickly changes to its upper limit

Because static module reaction speed is much slower, a current drop may occur when dynamic loop cuts out.

To acquire a shorter adjusting time for each current step. We set $\mathrm{KP}=300, \mathrm{KI}=2$.

Because the transformation of 1000A DCCT is $1: 2000$, we need to set the sampling resistance of DCCT to $200 \Omega$ to test the actual performance for each current step.

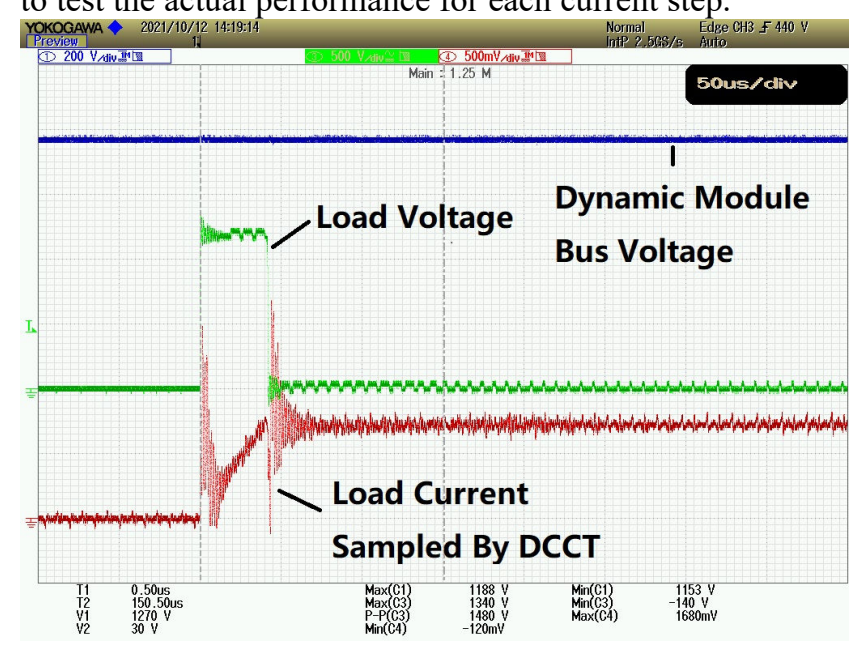

Fig. 14 Load current jumps from $0 \mathrm{~A}$ to $13.4 \mathrm{~A}$

Fig. 14 shows when load current jumps from $0 \mathrm{~A}$ to 13.4A. The time consumption of this process is about $150 \mu s$, which satisfies the time requirements for SCAN-
IEICE Electronics Express, Vol.xx, No.xx, xx-xx

V power supply.

But as Table.1 listed the biggest current step is $13.4 \mathrm{~A} \times 1.3=17.42 \mathrm{~A}$, the maximum inductance number is $3.876 \mathrm{mH} \times 1.1=4.2636 \mathrm{mH}$.

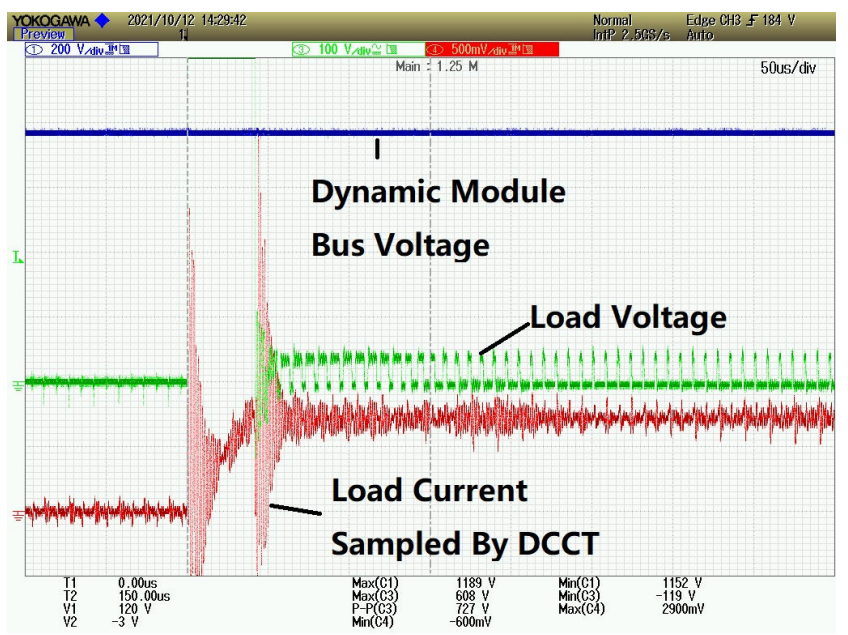

Fig. 15 Load current jumps from $0 \mathrm{~A}$ to $17.4 \mathrm{~A}$

From Fig. 15 it can be concluded that when load current jumps from $0 \mathrm{~A}$ to $17.4 \mathrm{~A}$ the total time consumption is about $150 \mu s$.

There are some oscillations when dynamic loop cut in and cut off. The oscillation frequency is about $770 \mathrm{kHz}$. We used loop analyzer to analyze the frequencyimpendence curve of transmission line and dummy load's inductor.

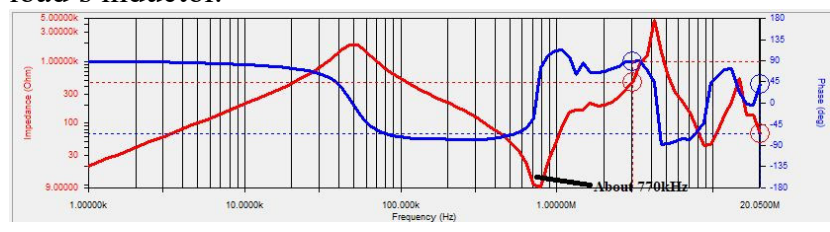

Fig. 16 Impendence-frequency curve of load series with transmission line

The actual magnet load curve is totally different from the dummy load, the bus voltage of dynamic module and static module remains stable. Therefore, we do not need to worry about the oscillations.

The highest dynamic module bus voltage appears when current jumps from $-700 \mathrm{~A}$ to $0 \mathrm{~A}$ (or $700 \mathrm{~A}$ to $0 \mathrm{~A}$ ). 


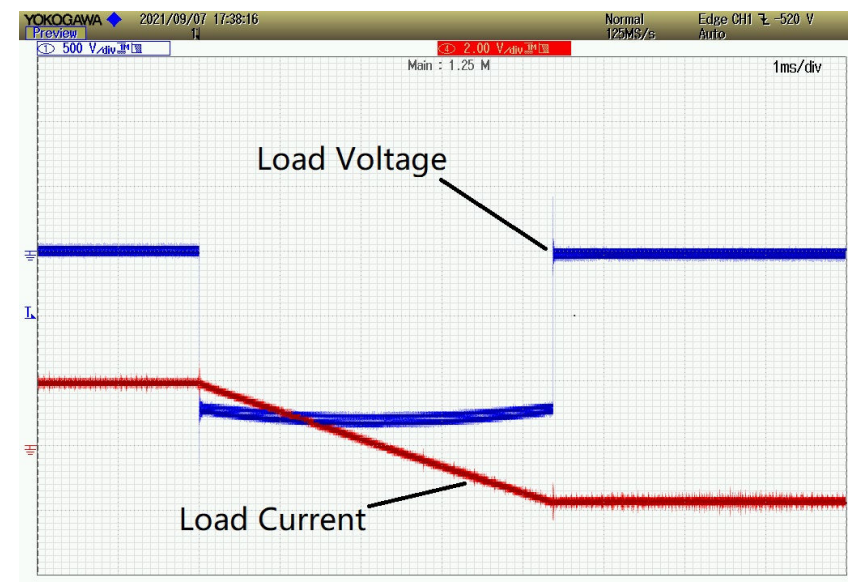

$\operatorname{Max}(\mathrm{C1}) \quad 420 \mathrm{~V} \quad \operatorname{Min}(\mathrm{C} 1) \quad-1640 \mathrm{~V}$

Fig. 17 Load current jumps from $+700 \mathrm{~A}$ to $-700 \mathrm{~A}$

Fig. 17 shows the dropping slope of load current is about $300 \mathrm{kA} / \mathrm{s}$. The peak voltage of dynamic module bus voltage reaches $1640 \mathrm{~V}$.

\section{Conclusion}

The super-fast scanning power supply requires a fastjumping speed as well as high resolution. Using phase shifted full-bridge circuits for static module can largely decrease the ripple current of load current. The key factor for dynamic module adjustment is the current difference, the smaller the differences will lead to a much quick adjusting time. This topology combines the advantages of static module and dynamic module together satisfies all these requirements.

\section{References}

[1] F. Cole, P. Livdahl, F. Mills and L. Teng. Design and Application of Proton Therapy Accelerator, Proc. Of IEEE Particle Accelerator Conference, 1987 pp. 1985-1987

[2] W.T. Chu, B.A. Ludewigt, and T.R. Renner, 'Instrumentation for treatment of cancer using proton and light-ion beams', Lawrence Berkeley Laboratory preprint, 1993

[3] T. Shirai et al., "Recent progress of new cancer therapy facility at NIRS," in Proc. IPAC, 2011, PP, 3604-3606.

[4] A R Smith, Vision 20/20: Proton therapy, Med. Phys. 36(2), 556$568,(2009)$

[5] J. M. Slater et al., "Development of a Hospital Based Proton Beam Treatment Center," Int. J. Radiation Oncology Biology Physics, Vol. 14, pp. 761-775.

[6] Gillin MT at el., "Commissioning of the discrete spot scanning proton beam delivery system at the University of Texas M.D. Anderson Cancer Center", Proton Therapy Center, Houston. Med Phys. 2010; 37:154-163.

[7] Biophysics Group, GSI Darmstadt, "Design, construction and first experiments of a magnet scanning system for therapy," GSI91-18, Report Juni 1991, ISSN 0171-4546, pp. 3-6.

[8] Bentzen S. M. (2006). Preventing or reducing late side effects of radiation therapy: radiobiology meets molecular pathology. Nat. Rev. Cancer 6, 702-713. 10.1038/nrc1950
[9] Wayne D Newhauser and Rui Zhang, "The physics of proton therapy," Physics in Medicine \& Biology, Vol. 60, No.8, March.2015

[10] M. Incurvati ET AL., "The Italian Hadrontherapy centre(CANO) a review of the power supplies system for conventional magnets," EPAC06, Edinburgh

[11] S.Nakamura et al., "Stabilization of the control system on magnet power supplies in J-PARC main ring," in Proc. 7th Meeting Particle Accelerator Soc. Jpn., 2010, pp. 587-589.

[12] C.Yamazaki et al., "Development of a power supply for the bending electromagnets on the heavy-ion facility at gunma university," in Proc. 7th Meeting Particle Accelerator Soc. Jpn., 2010, 99. 590-592.

[13] F. Caricchi et al., "Innovative control technique of a high-power $\mathrm{AC} / \mathrm{DC}$ convertor for particle accelerator," in EPE02, Toulouse, 2002.

[14] F. Jenni et al., "A Novel Concept for Highest Precision on Accelerator Power Supplies," 10th International Power Electronics and Motional Control Conference 2002

[15] T. Furukawa et al., "Development of Fast Scanning Magnets and Their Power Supply for Particle Therapy," IEEE Transactions on Applied Superconductivity, Vol. 24, No. 3, June 2014

[16] M. Incurvati et al., "Fast High-Power Power Supply for Scanning Magnets of CANO Medical Accelerator," EPAC 2008, 11th European Particle Accelerator Conference Genova

[17] Gerhard Breitenberger et al., "Power supply for a fast scanning system," IEEE Nuclear Science Symposium and Medical Imaging Conference, November. 1991

[18] G. Stover et al., "A raster scanning power supply system for controlling relativistic heavy ion beams at Bevalac Biomedical Facility," Proceedings of 1987 IEEE Particle Accelerator Conference, Washington, D.C., March 1987, Publising Services, IEEE, New York, pp. 1410-1412(1987)

[19] Y. Kurimoto et al., "Precision current control in accelerator magnets with a digital feedback system," IEEE Transactions on nuclear science, Vol. 61, No. 01, pp. 546-552, February. 2014.

[20] F. Jenni et al., "A Fully Digital PWM for Highest Precision Power Supplies,” European Power Electronics Conference 2001

[21] Zhu Xiaohui et al., "Research and design of high precision synchronization data acquisition system," Nuclear techniques, Vol. 37, No. 11, November. 2014

[22] B. Langenbeck etal., "The magnets and Power Supplies of the GSI Beam Scanning System for Heavy Ion Cancer Therapy," IEEE transactions on magnets, Vol. 32, No. 4, July. 1996

[24] Wang Dongxing et al., "A linearity error measurement method based on open-loop gain in DCCT," Journal of Northwest University (Natural Science Edition), Vol. 48, No. 3, June. 2018

[25] Wang Doing-xing: "On the Technologies of Super Large Current Magnet Power Supply in Parallel and Current Detection," Ph.D Dissertation, University of Chinese Academy of Sciences, Shanghai (2018)

[26] Wang Dongxing et al., "Ripple Rejection of Power Supply in Injection and Extraction Magnet in Proton Accelerator," Atomic Energy Science and Technology, Vol. 53, No. 9, Sep. 2019

[27] Shen Li et al., "Design of Injection Painting Bumper Magnets Pulse Power Supply for CSNS/RCS," Chinese Physics C (HEP \& NP) Vol. 32, Supplement I, March. 2008

[28] Peng Xu: "Multiphase Voltage Regulator Modules with Magnetic Integration to Power Microprocessors," Ph.D Dissertation, Virginia Polytechnic Institute and State University, Blacksburg (2002)

[29] P. Wong, F.C. Lee, P. Xu, and K. Yao, "Critical Inductance in Voltage Regulator Modules," CPES Annual Seminar, 2001, pp. 29-36

[30] Yu Ya-nan et al., "Development of a Programmable Scanning 
Magnet Power Supply," Nuclear Electronics \& Detection Technology, Vol. 34, No. 10, Oct. 2014 